\title{
TINDAK PIDANA PENYALAHGUNAAN NARKOTIKA OLEH REMAJA DI KABUPATEN GIANYAR
}

\author{
Luh Ketut Ayu Andayani, Anak Agung Sagung Laksmi Dewi, Luh Putu Suryani \\ Fakultas IImu Hukum Universitas Warmadewa, Denpasar-Bali, Indonesia \\ acutandayani1@gmail.com, laksmidewi.fhwjurnal@gmail.com,suryani.fhwjurnal@gmail.com
}

\begin{abstract}
Abstrak
Peningkatan penggunaan narkotika akhir-akhir ini menunjukkan angka yang semakin tinggi. Hal ini menimbulkan permasalahan baik bagi masyarakat umum maupun individu. Tindakan para pelaku penyalahgunaan narkoba sangat meresahkan, mulai dari lingkungan keluarga hingga lingkungan sekitar. Akibatnya, banyak anak yang mengalami kerusakan fisik dan mental. Tentu kasus sangat mempengaruhi masa depan mereka apa bila tidak ada pencegahan sejak dini. Penelitian ini bertujuan untuk mengkaji peraturan hukum tindak pidana penyalahgunaan narkotika oleh remaja di Kabupaten Gianyar dan mengkaji pertimbangan hakim dalam menjatuhkan sanksi pidana kepada pelaku penyalahgunaan narkotika di Kabupaten Gianyar. Penelitian ini dirancang dengan menggunakan penelitian hukum normatif dengan pendekatan perundang-undangan dan pendekatan konseptual dan masalah. Data yang digunakan adalah data hukum primer dan sekunder. Data diperoleh melalui penelitian lapangan dengan teknik catat dan dokumentasi. Selanjutnya data dianalisis secara deskriptif kualitatif. Hasil penelitian menunjukkan bahwa penerapan hukum pidana materiil oleh hakim dalam perkara Nomor 516/Pid.Sus/2015/PN.Mks sudah tepat dengan terpenuhinya unsur Pasal 127 Ayat (1) huruf a Undang-undang Nomor 35 Tahun 2009 tentang Narkotika. dengan menyatakan terdakwa secara sah dan meyakinkan bersalah melakukan tindak pidana penyalahgunaan narkotika. Pertimbangan hukum hakim dalam memutus perkara Nomor 516/Pid.Sus/2015/PN.Mks sudah tepat berdasarkan pertimbangan yuridis normatif dan sosiologis serta dengan melihat alat bukti yang sah.
\end{abstract}

Kata kunci: Narkotika, Remaja, Tindak Pidana

\begin{abstract}
The increase in the use of narcotics has recently shown a higher number. This creates problems for both the general public and individuals. The actions of drug abusers are very disturbing, starting from the family environment to the surrounding environment. As a result, many children are physically and mentally damaged. Of course, this will greatly affect their future. This study aims to examine the legal regulations for the criminal act of narcotics abuse by adolescents in Gianyar Regency and examine the judge's considerations in imposing criminal sanctions on narcotics abusers in Gianyar Regency. This research was designed using normative legal research with a statutory approach and a conceptual and problem approach. The data used were primary and secondary legal data. The data were obtained through field research using note-taking and documentation techniques. Furthermore, the data were analyzed descriptively qualitatively. The results showed that the application of material criminal law by the judge in case Number 516/Pid.Sus/2015/PN.Mks was fitting with the fulfillment of the elements of Article 127 Paragraph (1) letter a of Law Number 35 of 2009 concerning Narcotics by declaring the defendant legally and convincingly guilty of committing a crime of narcotics abuse. The judge's legal considerations in deciding the case Number 516/Pid.Sus/2015/PN.Mks were appropriate based on normative and sociological juridical considerations and by looking at valid evidence.
\end{abstract}

Keywords: Narcotics, Youth, Crime

\section{PENDAHULUAN}

Seluruh negara didunia sangat bergantung pada pemuda-pemuda sebagai penerus dan pondasi yang sangat sentral dalam memajukan negara (Nur Bintari \& Darmawan, 2016). Kaum muda adalah investasi utama dalam bidang pembangunan yang kedepannya akan merawat dan memajukan hasil dari pembangunan fisik dan paradigma sosial bangsa Indonesia yang wajib ditumbuhkan sebagai manusia yang utuh, sehingga menjadi ribadi yang mampu mengemban kewajiban sebagai warga yang baik bermatabat sesuai Undang-undang dasar 1945 dan Pancasila (Manggala et al., 2021) . 
Tanpa SDM segala sumber daya tidak akan berpungsi jika tidak dijalankan oleh orang yang memiliki bakan sehinggga Peran yang strategis terutama posisinya sebagai penerus cita-cita dan impian bangsa dengan mempunyai banyak keunggulan dan bakat dalam kemajuan teknologi dan ilmu pengetahuan, pada dasarnya remaja adalah pondasi penting yang akan menjadi penetu nasib bangsa di masa depan, maka dari itu sungguh sangat perlu dilakukan binaan khusus yang akan menjamin perkembangan fisiknya dan terutama mental yang seimbang dan padu. Pendidikan dan pergaulan adalah hal yang sangat penting dalam membentuk sebuah karakter penerus bangsa (Sudibyo \& Kiyamudin, 2019).

Pentingnya pada kaum muda yang ada pada masa peralihan antara masa kecil kemudian kemasa berikutnya yaitu pada masa dewasa dimana pada masa ini adalah masa yang sangat penting yang pada saat itu sangat mudah terpengaruh yang dapat dicirikan dengan perilaku menympang, keinginan untuk mencoba sesuatu yang baru, mengikuti perkembangan hidup yang selalu mengikuti tren masa kini seperti bergaya hidup mewah, selalu bersenang-senang ketempat hiburanyang walaupun terkesan biasa, tetapi ini adalah salah satu alasan yang banyak sudah terjadi yang bisa menjerumuskan ke hal negatife yang salah satunya penyalahgunaan narkoba. Sehingga jika pada masa kritis ini sudah terjerat maka masa depan yang seharusnya menjadi podasi akan hancur.

Kemudian sejalan pada bahasan tersebut, di Kabupaten Gianyar yang adalah wilayah hukum Polres Gianyar dimana dalam hal peningkatan jumlah penduduk termasuk kategori tinggi dan berada pada lokasi yang sangat strategis yang menjadi daerah pariwisata yang banyak dikunjungi turis asing maupun dosmetik. Tingkat sosial yang begitu tinggi tersebut juga akan sangat berpengaruh pada pergaulan dan pola hidup yang menyebabkan kebebasan dalam beraktifitas yang kemudian diikuti kegiatan kumpul didalam pergaulan yang bebas termasuk aktifitas perekonomian yang tinggi serta perdagangan dan kegiatan masyarakat yang aktif sehingga menjadi peluang tinggi terjadinya kasus pidana. Dibeberapa kasus cenderung tindakan ini melibatbatkan kaum muda sebagai pelaku utama dalam tindak pidana narkoba (Kamasa, 2014).

Berdasarkan observasi awal yang dilakukan pada Satuan Reserse Kriminal Polres Gianyar memperlihakan tren peningkatan dari tahun ke tahun, dimanan ini merupakan sesuatu yang sangat perlu dikaji mengapa biasa terjadi kenaikan padahal dengan pemberatan hukuman yang akan melanggar bisa terjadi kasus seperti ini dari beberap data yang sudah diambil terjadi fakta seperti ini pada tahun 2018 terjadi dua kasus, dilanjutkan tahun 2019 terdapat kenaikan tiga kasus, dan terakhir bulan April 2020 terjadi lima kasus dimana semua itu adalah kalangan muda yang masih dalam masa perlihan maka dari itu menimbulkan kewaspadaan dalam masyarkat dalam pertumbuhan dan potensi anak.

Sementara itu, kenyataan hukum yang terjadi menghukum yang dipidanakan di lembaga pemasyarakatan sehingga dari situ terdapat beberapa asumsi tindak kejahatan hanya berhenti sesaat dan terus tumbuh dalam kehidpan sehari hari dan belum bisa memberikan efek jera. Peraturan yang berlaku sebenarnya sudah sangat berat namun belum bisa memberikan efek penurunnan kasus bahkan terjai peningktan. Maka dari itu perlu adanya strtegi, dan terobosan yang dapat membuat tren tersebut turun. UU No. 35 Tahun 2009 yang ternyata tidak berpegangan pada penjatuhan hukuman yang tidak efektif namun semakin maksimalkan peran BNN untuk menangani kasus narkoba secara langsung, yang diharapkan agar dapt mencegah dan memberantas secara efektif dan efisien (Afifah, 2014); (Sholihah, 2015). Sekalipun sudah sejak lama dilakukan beberapa penelitian tentang pencegahan narkotika, namun sampai saat ini kasus penyalahgunaan narkoba terus terjadi. maka menyikapi hal itu peneliti ingin melakukan penelitian yang fokus pada kajian peraturan hukum tindak pidana penyalahgunaan narkotika oleh remaja di Kabupaten Gianyar dan menelaah pertimbangan hakim dalam menjatuhkan sanksi pidana terhadap perakara tindak pidana penyalahgunaan narkotika di Kabupaten Gianyar.

\section{METODE PENELITIAN}

Penelitian ini didesain menggunakan penelitian hukum normatif, dengan pendektan perundangundangan dan pendekatan masalah dan konseptual. Data yang digunakan adalah data hukum primer yaitu petikan putusan No. 212/Pid.Sus/2019/PN.Gin di Kabupaten Gianyar dan sekunder meliputi teoriteori yang diperoleh dari beberapa literatur ilmiah yang berkaitan dengan penelituan ini. Data diperoleh melalui penelitian lapangan dengan teknik mencatat dan dokumentasi, selanjutya data dianalisis secara deskriptif kualitatif (Moleong, 2005) 


\section{HASIL DAN PEMBAHASAN}

\section{Implementasi Hukum Pidana Putusan No.212/Pid.Sus/2019/PN.Gin ${ }^{1}$}

Suatu tindakan atau perbuatan yang diancam dengan pidana oleh undang-undang, bertentangan dengan hukum dan dilakukan dengan kesalahan oleh seseorang yang mampu bertanggung jawab (Erdianto \& Erdiansyah, 2016); (Chazawi, 2002). Menurut Moeljatno, (2002) perbuatan yang dilarang oleh suatu aturan hukum disertai ancaman (sanksi) yang berupa pidana tertentu, bagi barang siapa yang melanggar larangan tersebut. Istilah penyalahgunaan berasal dari kata dasar salah guna yang artinya melakukan sesuatu dengan tidak sesuai.

\section{M e n g a d i l i :}

a. Menyatakan Terdakwa Ardi Febrianto Alias Kabul yang sudah terbukti secara sah bersalah melakukan tindak pidana "Tanpa hak atau Melawan Hukum menjual Narkotika Golongan I

b. Menjatuhkan pidana terhadapTerdakwa Ardi Febrianto Alias Kabul oleh karena itu dengan Pidana Penjara selama enam tahun

c. Menjatuhkan pidana denda terhadap terdakwa Ardienfebrianto alias kabul sebesar satu milyar, jika tida dapat melunasinya maka diganti kurungan tiga bulan.

d. Dikurangkanya masa penahanan dari penangkapan sejak putusan

e. Memerintahkannya tetap berada didalam tahanan

f. Menetapkan barang bukti berupa:

1) Enam paket dari daun dan klip kecil berisi serbuk kristal warna putih diduga ganja dan sabu dengan berat keseluruhan 2,85 (dua koma delapan puluh lima) gram netto dengan perincian masing-masing paket: >1 (satu) paket dari plastik klip kecil berisi serbuk kristal warna putih diduga shabu terbungkus dengan kertas rokok Sampoerna mild seberat 0,15 (nol koma lima belas) gram netto setelah disisihkan seberat nol koma nol satu gram netto sebagai keperluan laboratorium dan sisa penyisihan adalah seberat 0,14 (nol koma empat belas) gram netto diberi kode "A"

2) 5 (lima) paket dari plastik klip kecil berisi serbuk kristal warna putih diduga shabu dengan berat masing-masing : > 0,5 (nol koma lima) gram netto setelah disishkan seberat 0,01 (nol koma nol satu) gram netto untuk keperluan Laboratorium dan sisa penyisihan adalah seberat 0,49 (nol koma empat sembilan) gram netto diberi kode "B". > 0,52 (nol koma lima dua) gram netto setelah disisihkan seberat 0,1 ( nol koma satu ) >. 0,42 (nil koma empat dua) gram netto setelah disisihkan seberat 0,1 (nol koma satu) gram netto untuk keperluan Laboratorium dan sisa penyisihan adalah seberat 0,41 (nol) koma empat satu ) gram netto diberi kode "D". >. 0,84 (nol koma delapan empat ) setelah disishkan seberat 0,1 (nol koma satu) gram netto untuk keperluan Laboratorium dan sisa penyisihan adalah 0,83 (nol koma delapan tiga ) gram netto diberi kode "E'. Satu buah HP Merk Mito warna coklat dengan dua sim card masing-masing Axis nomor :, 083114371208 dan Simpati nomor 081239761814 . 1 ( satu ) buah tas pinggang warna hitam, Satu buah potongan pipet warna putih yang ujungnya diruncingkan; Dirampas untuk dimusnahkan; Uang tunai sebanyak empat ratus ribu rupiah Dirampas untuk negara; Membebani Terdakwa untuk membayar biaya perkara sebesar Rp.5.000,- (lima riburupiah).

\section{Analisis}

Kasus yang menimpa Ardi Febrianto yang melakukan pelanggaran dan menyalahgunakan narkoba gol 1. Banyak fakta yang bisa dibahas satu persatu namun kami akan memulai dari pada fakta hukum yang terjadi dalam proses siding yang dinilai Hakim Majelis. Sudah sangat benar, alasan dikenakan karena yang bersangkutan positif menggunakan narkoba didasarkan hasil tes tersangka Ardi Febrianto dan otomatis menjdi pengguna sehingga untuk mendukung semua putusan tersebut harus memenuhi beberapa unsur. Artinya siapun orang ataupun sebuah lembaga sebagai subjek hukum yang mempunyai hak dan kewajiban yang kepadanya dapat dipertanggungjawabkan atas segala perbuatan yang dilakukan. Dalam kasus ini "barang siapa" yang artikan orang dan menunjukan kepada saudara 
terdakwa Ardi Febrianto yang mengaku dan menytakan semua benar akan propilnya. kemudian, dalam sidang Ardi Feebiatno dapat pula mengerti dan mejawab dan merespon secara benar segala yang ditanyakan yang akan hakin ajukan dan dari pada itu Ardi Frebianto dapat menilai bukti maupun keterangan yang diberikan oleh para saksi. Dengan demikian didalam siding yang sedang berlangsung diperoleh kenyataan dan terbukti bahwa saudara Ardi Frebianto sehat secara jesmani dan rohani dan tidak mengalami gangguan kejiwaan dan oleh hukum dianggap mampu mempertanggungjawabkan semua perbuatannnya. dari simpulan tersebut seluruh unsur-unsur dari dakwaan telah terpenuhi "Menggunakan narkotika bagi diri sendiri" dan menjatuhkan sanksi pemidanaan kepada terdakwa Ardi Febrianto

\section{Pertimbangan Hakim pada Putusan No.212/Pid.Sus/2019/PN.Gin.}

Hasil akhir dari proses persidangan yang panjang adalah putusan hakim maka dari itu putusan yang dihasilkan harus penuh dengan pertimbangan dan harus memenuhi unsur keadilan. Disini peran penting kecermatan dan ketelitian seorang hakim akan memutuskan sebuah perkara dengan dasar hukum sebagai acuan untuk membuat keputusan. Dimana putusan ini bisa dugunakan sebagai reperensi oleh para penulis sebagai bahan penelitiana dari hasil yang diperoleh dapat menjadi perbandingan untuk kasus yang mirip.

Pertimbangan pada kasus ini adalah: Menimbang, bahwa Saudara Ardi Febrianto diajukan di persidangan oleh Jaksa Penuntut Umum dengan dakwaan sebagaimana dalam surat dakwaan yaitu melanggar pasal sebagaimana dalam dakwaan; Kesatu Melanggar Pasal 112 ayat (1) UU RI No. 35 tahun 2009 dan Melanggar Pasal 127 ayat (1) huruf a UU RI No. 35 tahun 209;

Menimbang, bahwa didalam persidangan telah mendengarkan keterngan dari pada saudara Saudara Ardi Febrianto yang dibuat pada Berita Acara. Menimbang, bahwa pengakuan yang dikatakan Saksi dan pengakuan Saudara Ardi Febrianto telah sesuai dan saling berkaitan dan akhirnya menyimpulkan bahwa Terdakwa telah dibuktikan secara sah dan meyakinkan dikatakan salah dan melakukan Pidana "Penyalahgunaan Narkotika Golongan I "

Menimbang, bahwa oleh karena Saudara Ardi Febrianto dinyatakan terbukti secara sah dan meyakinkan bersalah melakukan perbuatan pidana sebagaimana didakwakan kepadanya maka Terdakwa haruslah dijatuhi hukuman yang sesuai atas perbuatan tersebut serta Terdakwa dikenakan pembayaran perkara sebagaimana dalam amar putusan ini;

Selanjutnya dalam proses kasus Majelis Hakim tidak ditemukannya alasan pembenaran maupan pemaaf yang mampu menghilangkan sifat melanggar hukum perbuatan Saudara Ardi Febrianto, maka Saudara Ardi Febrianto harus dijatuhkan pidana yang sesuai dengan perbuatannya yang didasarkan dengan rasa keadilan yang berlaku dalam masyarakat;

Menimbang, bahwa untuk menentukan besar kecilnya pidana yang akan diterima kepada diri Saudara Ardi Febrianto, maka perlu dipertimbangkan hal-hal yang memberatkan maupun hal-hal yang meringankan yaitu hal yang memberatkan terdakwa yaitu melanggar pemberantasan narkoba dan Rusaknya diri sendiri dan orang lai. Sedangkan Hal-hal yang meringankan Terdakwa yaitu mengaku akan perbiatannya dan santun di dalam mengikuti persidangan

\section{SIMPULAN DAN SARAN}

\section{Simpulan}

Berdasarkan analisis data diketahui bahwa penerapan hukum pidana materiil oleh Hakim terhadap tindak pidana Penyalahgunaan Narkotika Golongan I dalam Putusan Perkara Nomor 212/Pid.Sus/2019/PN.Gin telah tepat. Jaksa Penuntut Umum menggunakan 2 (dua) dakwaan, yaitu: Primair Pasal 112 Ayat (1) UU. RI. No 35 tahun 2009 tentang Narkotika Jo Pasal 132 (1) UU. RI. No 35 tahun 2009 tentang Narkotika, dan Subsidiair Pasal 127 Ayat (1) huruf a UU. RI. No 35 tahun 2009 tentang Narkotika. Pertimbangan hukum oleh Hakim terhadap tindak pidana Penyalahgunaan Narkotika Golongan I dalam menjatuhkan pemidanaan telah tepat karena hakim dalam perkara nomor 212/Pid.Sus/2019/PN. Gin menjatuhkan pemidanaan berdasarkan keterangan saksi, keterangan terdakwa, dan alat bukti surat yang menurut Pasal 184 KUHAP merupakan alat bukti yang sah. 


\section{Saran}

Dari simpulan penelitian di atas, adapun saran yang perlu peneliti sampaikan yaitu pemerintah harusnya mensosialisasi UU Narkotika terbaru, sehingga dapat meningkatkan eksistensi Badan Narkotika Nasional bersama dengan Polri. Selanjutnya diharapkan Optimalkan semua peran masyakat terutama desa atau banjar adat dengan cara melakukan sosialisai tentang kesadaran hukum bahaya narkoba.

\section{DAFTAR PUSTAKA}

Afifah, W. (2014). Pertanggungjawaban Pidana Anak Konflik Hukum. DiH: Jurnal Ilmu Hukum, $10(19), 48-62$.

Chazawi, A. (2002). Stelsel Pidana, Tindak Pidana, Teori-teori Pemidanaan\& Batas Berlakunya Hukum Pidana Bagian I. Raja Grafindo Persada: Jakarta.

Erdianto, \& Erdiansyah. (2016). Penerapan Sanksi Pidana dalam Penanggulangan Tindak Pidana Penghinaan Melalui Media Sosial Tinjauan Yuridis Tindak Pencemaran Nama Baik Melalui Media Sosial Berdasarkan Pasal 27 Ayat (3) Undang-Undang Nomor 11 Tahun 2008 Tentang Informasi dan Transaksi El. JOM Fakultas Hukum, 3(1), 1-15.

Kamasa, F. (2014). Kejahatan Kerah Putih Kontraterorisme dan Perlindungan Hak Konstitusi Warga Negara dalam Bidang Ekonomi. Jurnal Konstitusi, 11(4), 782-804.

Manggala, I. G. F., Dewi, A. A. S. L., \& Suryani, L. P. (2021). Tinjauan Yuridis Tindak Pidana Kebiri dalam Perspektif Hak Asasi Manusia. Jurnal Konstruksi Hukum, 2(1), 46-51.

Moeljatno. (2002). Asas-Asas Hukum Pidana. Jakarta. Rineka Cipta.

Moleong, L. J. (2005). Metode Penelitian Kualitatif. Remaja Rosdakarya.

Nur Bintari, P., \& Darmawan, C. (2016). Peran Pemuda Sebagai Penerus Tradisi Sambatan Dalam Rangka Pembentukan Karakter Gotong Royong. Jurnal Pendidikan Ilmu Sosial, 25(1), 57-76.

Sholihah, Q. (2015). Efektivitas Program P4Gn Terhadap Pencegahan Penyalahgunaan Napza. Jurnal Kesehatan Masyarakat, 10(2), 153-159.

Sudibyo, A., \& Kiyamudin, E. (2019). Perlindungan Hukum Terhadap Guru dalam Melaksanakan Tugas Keprofesionalannya Dikaitkan dengan Punishment dalam Mendisiplinkan. Paradigma, $1(2), 1-12$. 